\title{
Spatial and temporal patterns of benthic invertebrate communities in an intermittent river (North Africa)
}

\author{
A. Arab ${ }^{1}$, S. Lek ${ }^{2}$, A. Lounaci ${ }^{3}$, Y.S. Park ${ }^{2 *}$ \\ ${ }^{1}$ Université des Sciences et de la Technologie Houari Boumediènne, Faculté des Sciences Biologiques, BP 39, El Alia, Alger, Algeria \\ ${ }^{2}$ Laboratoire Dynamique de la Biodiversité (LADYBIO), UMR 5172, CNRS - Université Paul Sabatier, 118 route de Narbonne, 31062 Toulouse \\ cedex 4, France \\ ${ }^{3}$ Laboratoire d'Hydrobiologie, Faculté des Sciences Biologiques \& des Sciences Agronomiques, Département de Biologie, Université Mouloud \\ Mammeri de Tizi-Ouzou, Algeria.
}

\begin{abstract}
The spatial and temporal distribution patterns of benthic macroinvertebrates were studied in an intermittent river in Algeria (Chelif wadi, North Africa), by using the self-organizing map (SOM), an unsupervised artificial neural network. The samples were collected monthly at 8 sampling sites (630 to 20 m above sea level) and community variation was analysed in space and time. Overall, the study sites showed a very poor macroinvertebrate fauna: more than $60 \%$ of samples contained less than 11 species, and 99\% had less than 30 species. Furthermore, most species displayed very low abundance: $66 \%$ of the species were represented by less than 20 individuals (abundance). Among the identified taxa, Chironomidae was the dominant taxon at all sampling sites except at the most upstream site (630 m a.s.l.) where it was replaced by Coleoptera. Concerning monthly changes, the species richness was very low in August and October. Through the learning process of the SOM, samples were classified into four clusters by the SOM, and the classification was mainly related to the location of the sampling sites. Benthic macroinvertebrates were divided into four classes, which revealed the influence of pollution on their longitudinal distribution in this stream. According to the distribution gradients of the environmental variables on the SOM map, their influence on the classification of the sampling sites could be assessed effectively.
\end{abstract}

Keywords : macroinvertebrates, intermittent stream, species richness, self-organizing map, artificial neural network, North Africa.

\section{Introduction}

The distribution of benthic macroinvertebrates is largely related to environmental factors (Richards et al. 1993, Tate \& Heiny 1995, Benbow et al. 2003), and their communities change both spatially and temporally (Hynes 1970, Townsend \& Hildrew 1994). Changes in the benthic community structure were often assessed by examining taxonomic compositions along the stream continuum (Grubaugh et al. 1996, González et al. 2003). Spatial variations have been attributed to habitat characteristics (e.g., Brown 1984, Brown et al.

\footnotetext{
* Corresponding author :

E-mail:park@cict.fr
}

1995, Boyero 2003), but also to stochastic temporal fluctuations of the environment (Ives \& Kopfer 1997, McIntosh et al. 2003). Based on the dynamic equilibrium concept (Curry 1972), streams form a balance between physical parameters (such as width, depth, velocity, and sediment load), and biological factors. Temporal variations in community assemblages can result from habitat seasonality, organism phenology, and/or disturbance. Flooding represents the dominant type of natural disturbance along most river corridors (Welcomme 1979, Puckridge et al. 1998, Arscott et al. 2003) and it is likely that all stream ecosystems are disturbed by fluvial forces to some degree (Reice 1985, Statzner et al. 1987, Ward 1989). Changes in hydraulic stress due to tributary confluences or changes in channel geometry have also been suggested to influence 
longitudinal patterns of invertebrate diversity (Statzner \& Higler 1986, Arscott et al. 2003). Finally, thermal patterns in rivers are also thought to be a major factor structuring benthic macroinvertebrate communities (Vannote \& Sweeney 1980, Ward 1985, Arscott et al. 2003).

The Mediterranean basin is characterized by an extensive range of physical conditions, including severe flooding and droughts (Pires et al. 1999). The thermal variations are sometimes brutal, and the irregular and violent precipitations are concentrated over short periods. Mediterranean rivers are characterized by the irregularity of the flows and brutal hydrological fluctuations. The annual flow mode is marked by a maximum in spring and autumn, and a severe low water level in summer (Giudicelli et al. 1985).

In arid and semi-arid regions, intermittent streams are the dominant type of streams (Comin \& Williams 1994), and are ubiquitous in areas with Mediterranean type climates (Gasith \& Resh 1999). The drying process poses several physico-chemical and biological challenges to the biota of intermittent streams (Williams 1996). The patterns of water disappearance are of fundamental importance, whether they are predictable (i.e., part of a stable cycle) or unpredictable (i.e., linked to the vagaries of local climate) (Williams \& Hynes 1976, Wiggins et al. 1980, Delucchi 1988). The length of the dry period thus influences the decrease in habitat size. Temperature changes result in subtle changes in water density which may affect the smaller instars of insects, and ionic concentration tends to rise significantly as temporary water dries out, which may affect $\mathrm{pH}$. Oxygen will be further affected by changes in water temperature which will increase as the water disappears in summer-dry water bodies (e.g., autumnal ponds, Wiggins 1973), while it will decrease in winter-dry bodies (e.g., aestival ponds, Daborn \& Clifford 1974).

The running water ecosystems of Northern Algeria (Mediterranean basin) are physically very diverse, not only between geographical areas but also between upstream and downstream sections. In this area, the dominating feature of the rivers is the irregularity of the flows. Floods and low water levels are the two major events to which these lotic ecosystems are subjected, so temporary biotopes are largely dominant. In Algeria, aquatic organisms are severely affected by the aestival drought. Most early works on the hydrosystems of North Algeria were mainly devoted to the description of species, but few concerned their ecology or biogeography (Reiche 1869, Seurat 1922, Navas 1929). More recently, some studies have been conducted on the fauna of inland waters of this country (Gagneur et al. 1986, Arab 1989, Lounaci et al. 2000). The objective of this work was thus to determine the spatial and temporal patterns of benthic macroinvertebrate assemblages in an intermittent stream in North West Algeria.

\section{Materials and methods}

\section{Data collection}

Benthic macroinvertebrates were collected monthly at 8 sampling sites in the Chelif river, North West Algeria (Fig. 1), from December 1989 to December 1992. The Chelif is the wadi which drains part of the high plateau, and it is one of the longest rivers in North Africa (length : $700 \mathrm{~km}$ ). The Chelif plain receives only moderate, undependable rainfall (average : 400 $\mathrm{mm}$ annually), and evaporation is intense. The lower reaches of the river basin are, however, cultivated with the aid of irrigation. Three main dams have been constructed on the Chelif system at Ksar el-Boukhari (1932), Ech-Cheliff (El-Asnam; 1932), and El-Khemis (1939). The Chelif drainage basin covers a total area of $44630 \mathrm{~km}^{2}$. The altitude of the sampling sites ranged from $630 \mathrm{~m}$ (St1) to $20 \mathrm{~m}$ a.s.1. (St8). Generally, an aestival absence of flow occurs from May to November, if there is not enough rainfall. Especially, sites St4 and St8 were highly influenced by the lack of flow. The general characteristics of the physical factors are summarized in Table 1.

Macroinvertebrates were collected using a Surber sampler $(30 \mathrm{~cm}$ x $50 \mathrm{~cm}$, mesh size $250 \mu \mathrm{m})$. At each sampling time, 6 samples were collected as replicates. The samples were preserved in $5 \%$ formalin and in-

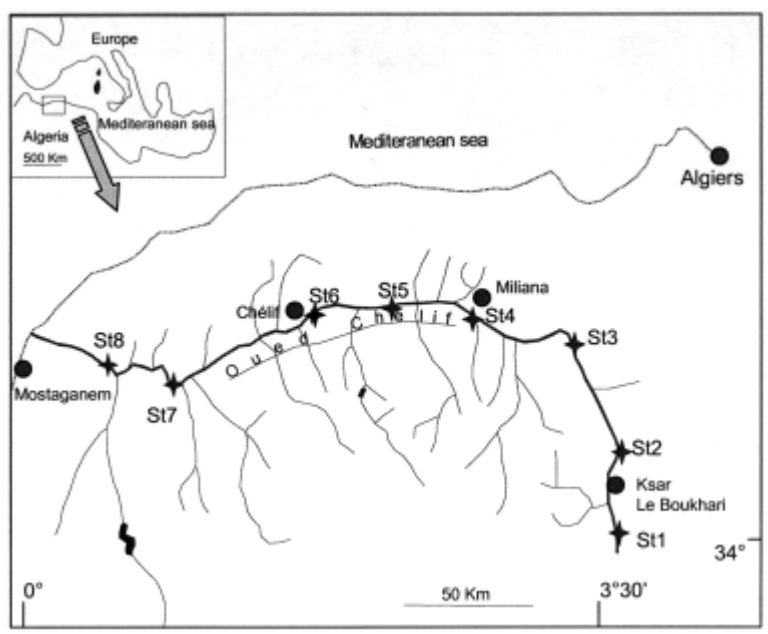

Fig. 1. Map of the study area, and location of the sampling sites. 
Table 1. Main environmental characteristics of the sampling sites.

\begin{tabular}{lcccccccc}
\hline \multirow{2}{*}{ Variables } & \multicolumn{10}{c}{ Sampling sites } \\
\cline { 2 - 10 } & St1 & St 2 & St3 & St4 & St5 & St6 & St7 & St8 \\
\hline Altitude (m) & 630 & 600 & 355 & 230 & 150 & 105 & 45 & 30 \\
Width range (m) & $3-18$ & $5-20$ & $2-5$ & $2-5$ & $5-12$ & $1-4$ & $3-15$ & $0.5-1$ \\
Mean depth (cm) & 50 & 40 & 50 & 50 & 45 & 40 & 30 & 35 \\
Distance from source (km) & 300 & 325 & 379 & 424 & 457 & 487 & 561 & 611 \\
Dry months per year & 2 & 2 & 0 & 5 & 1 & 1 & 0 & 4 \\
\hline
\end{tabular}

vertebrates were identified to species or morphospecies level. Due to the low abundance of the fauna in the study areas, the samples collected over three years were summarised monthly at each sampling site and used in the data analysis. Substrate composition (\%) at each sampling sites was measured by direct observation: pebble $(25-50 \mathrm{~mm})$, gravel $(5-25 \mathrm{~mm})$, sand $(0.06-5$ $\mathrm{mm})$, silt $(<0.06 \mathrm{~mm})$, and organic matter.

\section{Community assemblages}

To evaluate the differences in community structures between sampling sites from upstream to downstream areas, community indices such as species richness and Shannon diversity index were evaluated at each sampling site. A Kruskal-Wallis test was conducted to test significant differences of species richness between clusters defined by a self-organising map (see below). Mann-Whitney tests were conducted to evaluate significant differences of community indices between sites. Statistical analyses were carried out using the statistical software STATISTICA (StatSoft 2002).

\section{Modelling procedure}

The dataset of macroinvertebrate assemblages was applied to an adaptive learning algorithm, the self-organizing map (SOM, unsupervised neural network), to bring out distribution patterns of communities in space and time. The species abundances were scaled between 0 and 1 in the range of the minimum and maximum values within a species, after a log-transformation process in order to reduce variations in abundance. The SOM approximates the probability density function of the input data (Kohonen 2001). The SOM has found wide applications in the fields of data exploration, data mining, data classification, data compression, and biological modelling, due to its properties of neighbourhood preservation and local resolution of the input space proportional to the data distribution. The SOM consists of input and output layers connected with computational weights (connection intensities). The array of input neurons (i.e. computational units) operates as a flow-through layer for the input vectors, whereas the output layer consists of a two-dimensional network of neurons arranged in a hexagonal lattice. In the learning process of the SOM, the biological data were initially subjected to the learning network. Then, the weights were trained for a given dataset of the network, each neuron $k$ of the output layer computes the summed distance between weight vector $\boldsymbol{w}$ and input vector $\boldsymbol{x}$. The output layer consists of $N$ output neurons (i.e., computational units, $24=6 \times 4$ in this study) which usually constitute a 2D grid for better visualization. The output neurons are considered as virtual units to represent typical patterns of the input dataset assigned to their units after the learning process. Among all $N$ virtual units, the best matching unit (BMU) which has the minimum distance between weight and input vectors becomes the winner. For the BMU and its neighbourhood units, the new weight vectors are updated by the SOM learning rule. This results in training the network to classify the input vectors by the weight vectors they are closest to. The virtual assemblages can be obtained by denormalizing weight vectors trained in the learning process. To define clusters between virtual units of the SOM map, a hierarchical cluster analysis was used with Ward's linkage method with Euclidean distance measure. Based on linkage distances, the map was classified into several groups indicating differences of assemblages at different scales. During the learning process of the SOM, the map units that are topographically close in the array will activate each other to learn something from the same input vector. The weight vectors tend to approximate the probability density function of the input vector. Therefore, the 
visualization of these vectors is convenient to understand the contribution of each input variable to the clusters on the trained SOM (Kohonen 2001, Park et al. 2003a). To analyse the contribution of variables to cluster structures of the trained SOM, the value of each input variable (component) calculated during the training process was visualized in each unit on the trained SOM map on a grey scale.

\section{Results}

\section{Community assemblage}

Overall, 175 species were identified from the various samples. Nevertheless, more than $60 \%$ of the samples contained less than 11 species, and $99 \%$ had less than 30 species (Fig. 2a). In addition, most species displayed very low abundance : $66 \%$ of the species were represented by less than 20 individuals (Fig. 2b).

Among the identified taxa, Chironomidae was the dominant taxon at all sampling sites, except site St1 where Coleoptera was dominant (Table 2). The taxonomic richness of macroinvertebrates showed fluctuations along the Chelif course. It was the highest at site St2 (71 species), decreased at the downstream site St3 (54 species), and showed the lowest value (14 species) at site St 4 where water was heavily polluted. Downstream of site St4, the taxonomic richness increased gradually. Sampling sites St1-3 showed relatively high a)

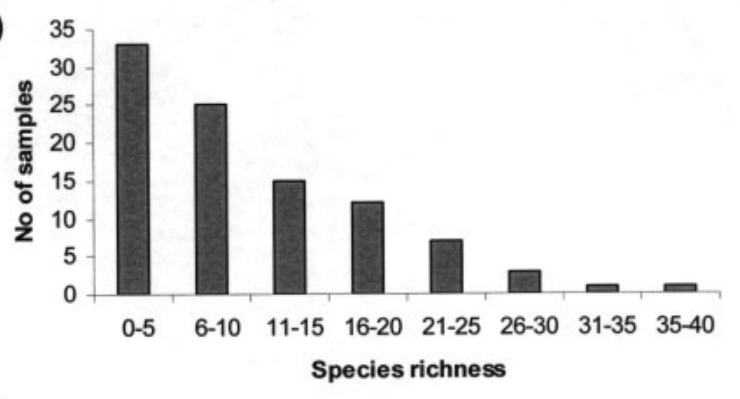

b)

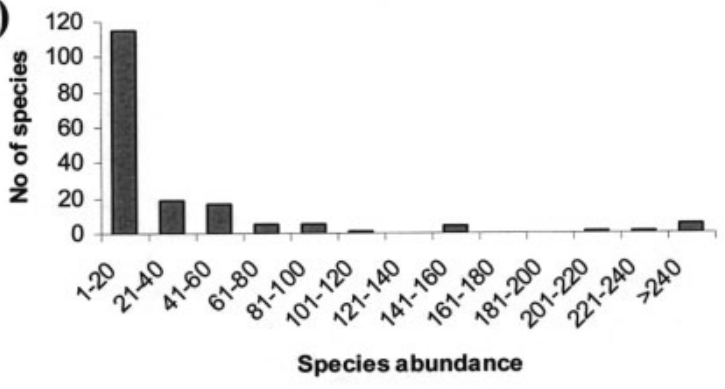

Fig. 2. Distribution pattern of species richness in samples (a) and relations between species abundance (ind. per sample) and species richness (b).

species richness, whereas sampling site $\mathrm{St} 4$ showed

Table 2. Species richness in different taxa at the various sampling sites.

\begin{tabular}{lrrrrrrrr}
\hline \multirow{1}{*}{ Taxon } & \multicolumn{10}{c}{ Sampling site } \\
\cline { 2 - 10 } & St1 & St2 & St3 & St4 & St5 & St6 & St7 & St8 \\
\hline Ephemeroptera & 4 & 9 & 6 & 2 & 6 & 3 & 6 & 7 \\
Plecoptera & 0 & 1 & 1 & 0 & 0 & 0 & 0 & 0 \\
Trichoptera & 0 & 3 & 7 & 1 & 1 & 0 & 1 & 0 \\
Coleoptera & 17 & 5 & 0 & 0 & 1 & 2 & 4 & 3 \\
Oligochaeta & 2 & 9 & 12 & 5 & 7 & 8 & 8 & 5 \\
Odonata & 8 & 2 & 2 & 0 & 1 & 1 & 2 & 1 \\
Hemiptera & 5 & 4 & 2 & 1 & 3 & 4 & 3 & 4 \\
Diptera* & 10 & 17 & 11 & 2 & 7 & 7 & 9 & 13 \\
Chironomidae & 5 & 21 & 13 & 3 & 11 & 10 & 18 & 24 \\
\hline Total & 51 & 71 & 54 & 14 & 37 & 35 & 51 & 57 \\
\hline
\end{tabular}

* Diptera except Chironomidae 


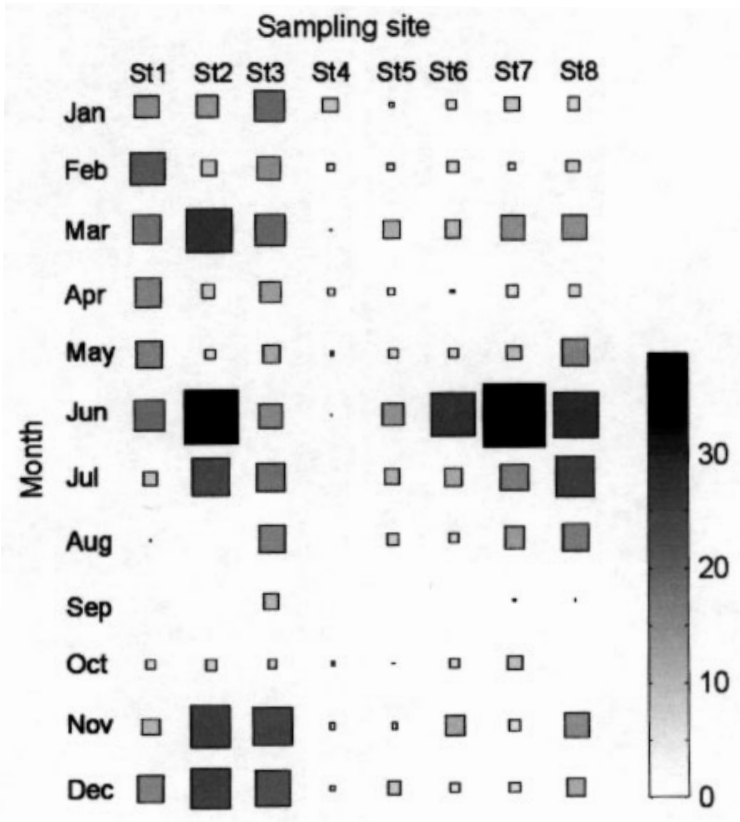

Fig. 3. Changes of species richness at different sampling sites at different months. Large dark squares represent high species richness, whereas small light ones indicate low values, ranging from 0 to 39 .

the lowest value (Fig. 3). Considering monthly changes, the species richness was very low around September (August and October). During this period, no species were collected at sampling sites St1, 2, 4-6, 10. The species richness was the highest in June at most sampling sites. The Shannon diversity index which takes account of the specific richness as well as the abundances showed the same patterns (Fig. 4a). The index showed the highest value at the upstream site

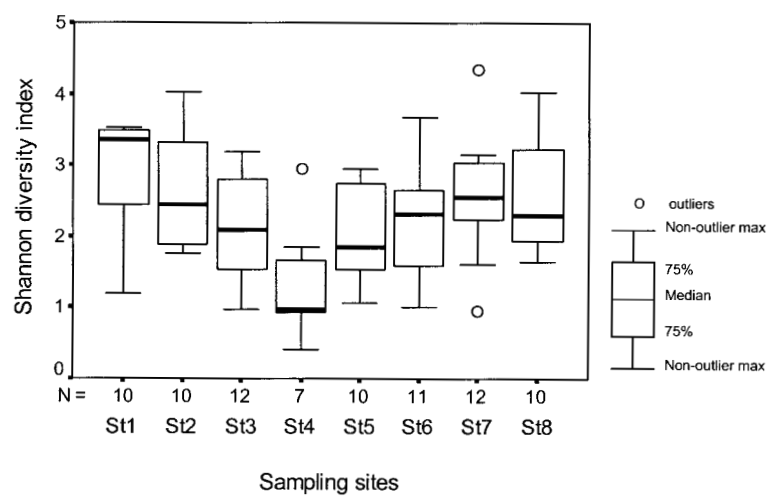

Fig. 4. Box-plots showing differences of species diversity index (Shannon) at different sampling sites. Mann-Whitney test for Shannon diversity index between sampling sites were conducted (see Table 3).

St1, and it decreased progressively to site St4 (lowest values). The Shannon index then increased gradually from site St5 to site St8, although there were some variations. At downstream areas, the differences were not significant (Mann-Whitney test, $\mathrm{p}>0.05$ ) (Table 3).

\section{Community distribution patterns}

Macroinvertebrate communities were patterned on the $2 \mathrm{D}$ lattice map through the leaning process of the SOM with abundance of species (Fig. 5a). Overall, communities were classified according to the location of the sampling sites and monthly densities, although large variations were observed. For example, most samples from site St1 were located in the middle-left areas of the SOM, and samples from mid-downstream areas (i.e., St4-8) were grouped in the upper right areas of the SOM map, whereas samples from summer and autumn were grouped together in the upper-left areas

Table 3. Summary of Mann-Whitney test for Shannon diversity index between sampling sites.

\begin{tabular}{rrrrrrrr}
\hline Site & St2 & St3 & \multicolumn{1}{c}{ St4 } & \multicolumn{1}{c}{ St5 } & St6 & St7 & St8 \\
\hline St1 & 0.526 & 0.074 & $0.012^{*}$ & $0.042^{*}$ & $0.0178^{*}$ & 0.325 & 0.213 \\
St2 & & 0.066 & $0.004^{* *}$ & 0.057 & 0.398 & 0.895 & 0.356 \\
St3 & & & $0.031^{*}$ & 0.46 & 0.712 & 0.166 & 0.644 \\
St4 & & & & $0.09^{*}$ & $0.017^{*}$ & $0.009^{* *}$ & 0.053 \\
St5 & & & & & 0.533 & 0.074 & 0.295 \\
St6 & & & & & & 0.268 & 1.000 \\
St7 & & & & & & & 0.386 \\
\hline
\end{tabular}

${ }^{*} \mathrm{p}<0.05,{ }^{* *} \mathrm{p}<0.01$ 
a)

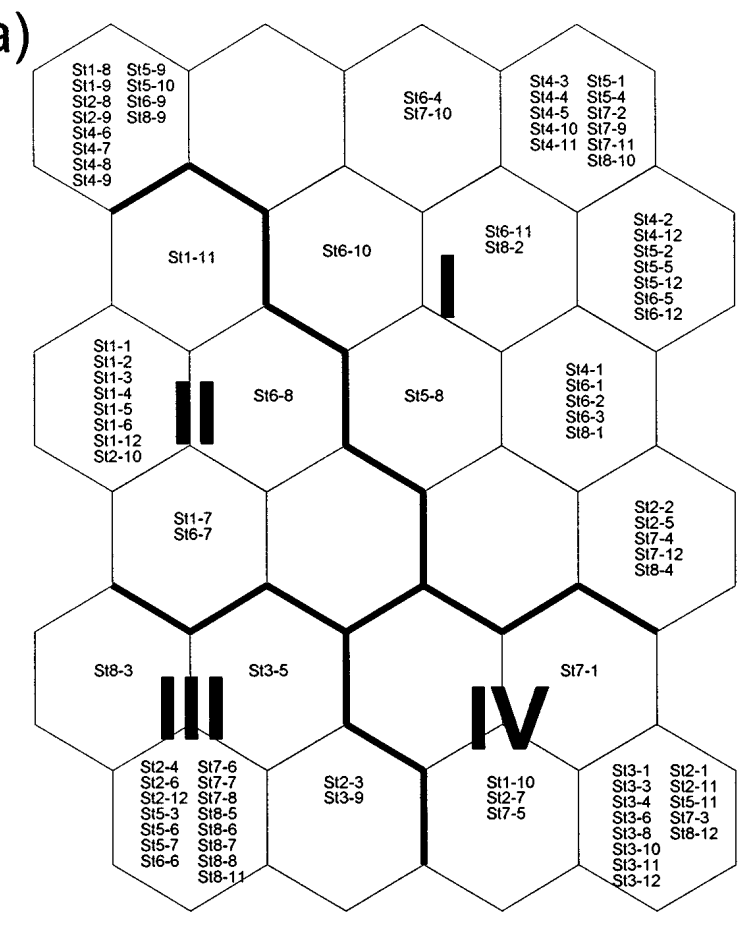

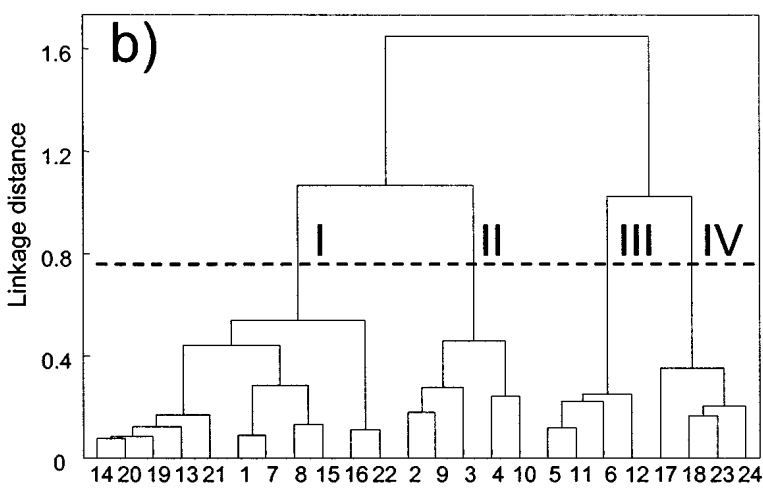

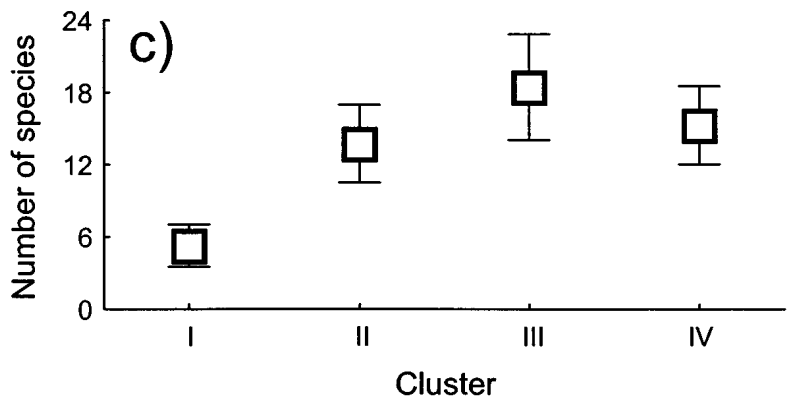

Fig. 5. (a) Classification of samples through the learning process of the self-organizing map (SOM). (b) The SOM units were further clustered using hierarchical cluster analysis with a Ward linkage method and a Euclidean distance measure. (c) Differences in species richness between different clusters defined in the SOM. Kruskal-Wallis test was conducted for the evaluation of significant differences in species richness between clusters $(\mathrm{p}<0.001)$.

of the SOM. Samples collected at sites St1, 2, 4-6, 8 in August-October were grouped together and distinguished from others in the upper-left areas of the SOM map. Theses samples were characterised by low species richness.

A hierarchical cluster analysis with a Ward linkage method was used to define cluster boundaries among the SOM units (Fig. 5b). Samples in the SOM map were further classified into four groups (I-IV) according to their community similarities. Cluster I was characterised by samples from downstream areas, cluster II was identified by samples from site St1, cluster III was characterized by samples from sites St 3 and $\mathrm{St} 8$, and cluster IV was characterized by site St3. Cluster I showed the lowest species richness and significantly differed from other clusters (Kruskal-Wallis test, $\mathrm{p}<0.001$ ), whereas there were no significant differences between clusters II, III, and IV (Fig. 5c).

After the SOM learning process, estimated species profiles were obtained from each SOM unit, and summarized in each cluster. Through these profiles, we were able to evaluate the relative importance of each species in determining the community patterns in the
SOM map. Figure 6 shows typical distribution patterns of species in each cluster. The distribution pattern of each species on the SOM units was assigned to one of four patterns based on the occurrence cluster of the highest abundance areas. Cluster I was mainly characterised by Limnodrilus hoffmeisteri, cluster II was dominated by Micronecta scholtzi and Panarais sp., cluster III by Baetis neglectus, Cloeon gr. dipterum, and Cricotopus bicinctus, and cluster IV was characterised by Baetis pavidus, Caenis luctuosa, Rheocricotopus chalybeatus, and Tubifex tubifex.

\section{Differences of substrate composition}

Substrate composition of sampling sites were visualised in different clusters defined by the SOM trained with invertebrate data (Fig. 7). Silt showed high values in clusters I and II, and low values in clusters III and IV. Pebbles and gravels had high values in cluster III. In cluster IV, there were no significant differences between substrate types, although sand showed the highest value. All substrate types excluding organic matter were significantly different between clusters (Kruskal-Wallis test, $\mathrm{p}<0.001$ ). 


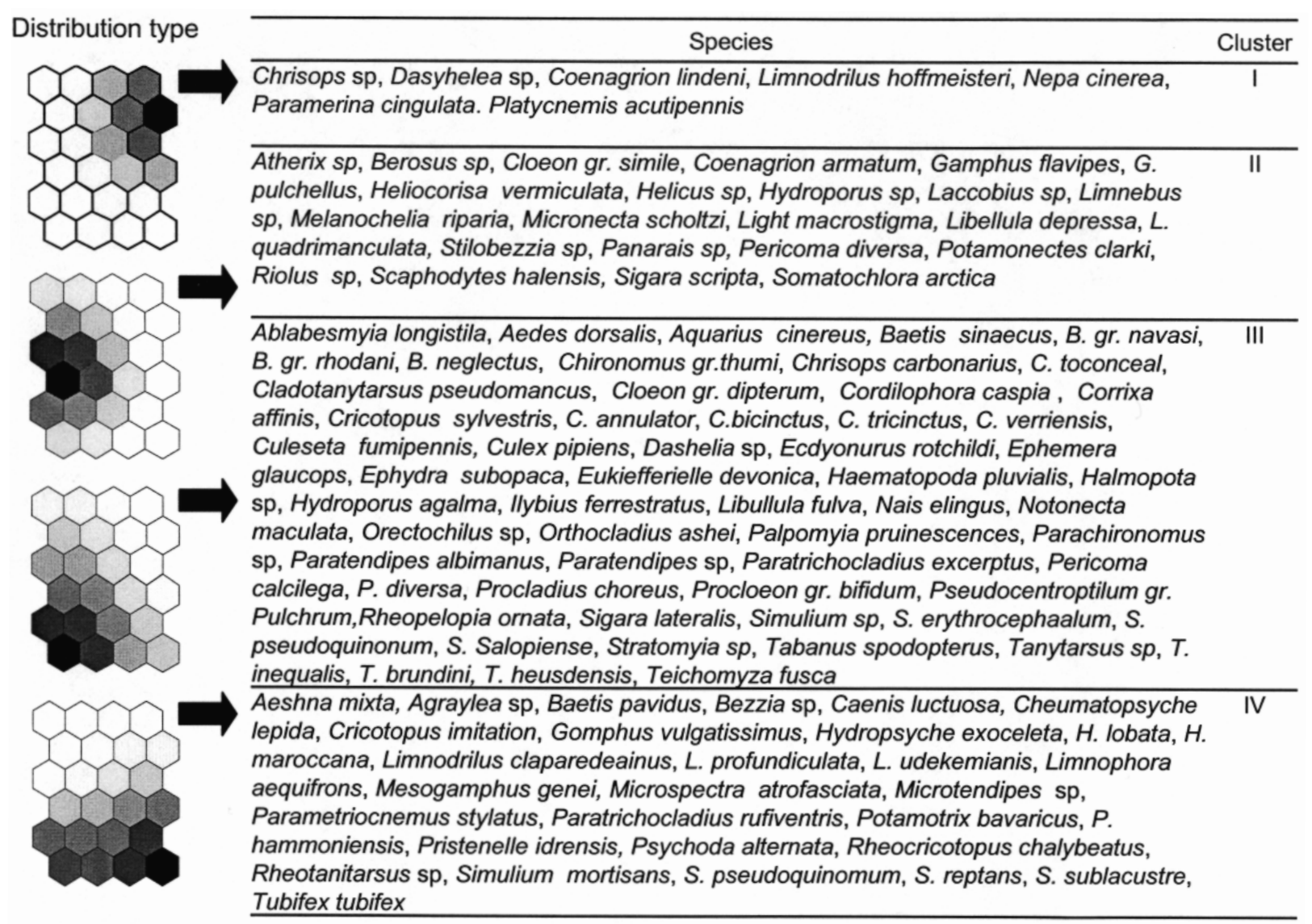

Fig. 6. Distribution patterns of species in each cluster defined in the SOM map. Their distribution patterns indicate their contribution to the organisation of patterns defined through the SOM. Dark represents high abundance of species, and light represents low abundance.

\section{Discussion}

Highly heterogeneous ecosystems affect the relationship between spatial and temporal variation in environmental constrains and the responses by organisms to them (Milne 1991). Numerous studies have focused on the biological implications of these constraints in terms of processes and mechanisms (Palmer et al. 1995, Palmer \& Poff 1997, Townsend et al. 1997). The community structure is changed by perturbations in the environment and the degree of structural change is used to assess the intensity of the environmental stress (Hellawell 1986). Species richness is influenced by environmental conditions (Legendre \& Legendre 1998). A stable environment contains more species and more niches, because a more stable environment involves a higher degree of organization and complexity of the food web (Margalef 1958). The

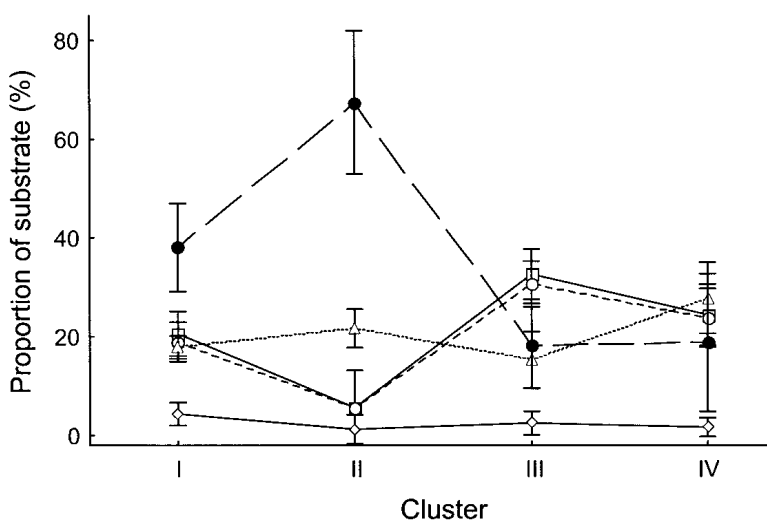

Fig. 7. Differences of substrates (pebble; $\square$, gravel; $\bigcirc$, sand; $\triangle$, silt; $\bigcirc$, organic matter; $\diamond$ compositions at different clusters defined by the SOM. Kruskal-Wallis test: Pebble $(\mathrm{KW}-\mathrm{H}(3,96)=$ $23.43, \mathrm{p}<0.001)$, gravel $(\mathrm{KW}-\mathrm{H}(3,96)=24.43, \mathrm{p}<0.001)$, sand $(\mathrm{KW}-\mathrm{H}(3,96)=21.57, \mathrm{p}<0.001)$, silt: KW-H $(3,96)=28.41, \mathrm{p}<$ $0.001)$, and Organic matter $(\mathrm{KW}-\mathrm{H}(3,96)=5.13, \mathrm{p}=0.163)$. 
niche of a species is the set of environmental conditions that the species does not share with any other sympatric species, so species richness is concerned with the number of niches (Hutchison 1957). Intermittent streams in the area may not have a distinct faunal assemblage that is adapted to drying conditions - under a Mediterranean-type climate characterized by unpredictable annual rainfall patterns, intermittent streams may not dry completely each summer and perennial streams may occasionally dry during droughts. Benthic macroinvertebrates in intermittent streams have been partitioned into 3 groups of taxa: permanent, facultative (i.e., lotic/lentic generalists), and temporary for non-flowing conditions (Williams \& Hynes 1977). Schneider and Frost (1996) argued that the persistence of many species in temporary aquatic systems with a wide range of wetted habitat duration may be possible, largely through life history adaptation, rather than from random processes such as colonization or extinction, or from biotic interactions with other species. In this context, many species may persist in such habitats as long as they complete the aquatic stage of their life cycles before the loss of critical aquatic habitat (Wiggins et al. 1980, Schneider \& Frost 1996, Williams 1996).

The benthic macroinvertebrate fauna was qualitatively and quantitatively poor at our study sites. Thus, defining monthly and yearly changes of macroinvertebrate communities was a difficult task. We therefore tried to bring out monthly patterns of communities after pooling yearly data into monthly data. Low species abundance is common in intermittent streams of North Africa (Arab 1989, Lounaci et al. 2000, Belaidi et al. 2004), because of unstable environmental conditions, chiefly the frequent absence of flow, and insufficient water levels when it flows. As a result, intermittent streams usually host less species than permanent streams (Wrigth et al. 1984, del Rosario \& Resh 2000, Bonada 2003), although some contrasting results have been reported by comparing richness at permanent and temporary sites. For instance, similar richness were observed between the two stream types (Legier \& Talin 1973, Boulton \& Suter 1986, Miller \& Golladay 1996), and higher richness occurred in pools of temporary streams compared to a permanent stream (Dieterich \& Anderson 2000). These contrasting results could be due to different concepts of «temporary sites» in different works, as some authors consider them as sites that dry up completely in summer, whereas others refer to rivers that have isolated pools during the dry period (Bonada 2003). The dry season length has been recognized as one important factor determining the biolo- gical diversity in these streams (Williams \& Hynes 1976, Abell 1984, Williams 1996, Bonada 2003). Thus, further comprehensive studies on the effects of frequent absence of flow and insufficient flow on benthic communities are needed, probably supporting the intermediate disturbance hypothesis (Connell 1978), which assumed that high species diversity is a result of intermediate frequency of disturbance, while either too low or too high frequency of disturbance will reduce biodiversity (Jørgensen \& Padisak 1996).

The species richness of Diptera (with high Chironomidae richness) was relatively high at most of our sampling sites, except at the upstream site St1, probably because of a pollution gradient. During the field survey, we evaluated the water quality of sampling sites according to the suspended materials and the colour of water, ranging from 5 (relatively clean, transparent) to 1 (very polluted, dark water). Site St1 was the cleanest areas (5), whereas site St4 had the worst water quality (1). Water quality at other sites ranged between the estimates for these two sites. Species colonization of intermittent streams is dependent on environmental factors such as drying conditions, and on behavioural and/or physiological adaptations to habitat drying. Tolerance of species to drying by behavioural and/or physiological adaptations is the basis for studies that have concluded that the assemblages found are comparable to those of nearly perennial streams (Williams 1987). With the loss of water, aquatic insects counter the 'terrestrialisation' of their habitat by means of physiological tolerance and migration. Although the adaptations shown by individual species are varied, members of a same major taxonomic groups tend to have similar stages in their life cycles that resist drying out. Thus, mayflies, lestid odonates, and mosquitoes largely survive drought as eggs (Lehmkul 1973, Wood et al. 1979), many beetles and hemipterans survive as adults (Macan 1939), and stoneflies survive by diapausing as early instar nymphs (Harper \& Hynes 1970). Chironomids may diapause as larvae or eggs (Thienemann 1954). Pires et al. (2000) reported that Diptera was the dominant taxa in intermittent streams in Portugal and concluded that Diptera dominated the fauna because they are more tolerant to drought conditions and have more efficient recolonization mechanisms. Among the study sites, sites St1-3 showed the highest Shannon diversity. However, diversity decreased drastically at site St4, which is located $25 \mathrm{~km}$ downstream of Miliana, and $5 \mathrm{~km}$ from Ain Defla. This was almost certainly due to both anthropogenic and natural disturbances of the aquatic ecosystem, because site St 4 suffered from domestic and industrial pollution. In addition, the wa- 
ter supply was insufficient at this site to provide habitats to aquatic organisms, and for self-purification. Site $\mathrm{St} 5$ was also influenced by industrial waste and showed low values of Shannon diversity and species richness. However, the indices increased in downstream areas (St6-8), and became similar to those calculated at sites St1-3. This pattern suggests that water quality was improved towards downstream reaches, due to self-purification.

The SOM showed its ability to classify input vectors as well as to visualize relationships among input variables in their contribution to the classification (i.e., Chon et al. 1996, Park et al. 2001, 2003a, 2003b, 2003c, 2004, Giraudel and Lek 2001, Céréghino et al. 2003). A clear gradient of a variable in the SOM map represents a high contribution gradient to the classification of input vectors. In this study, the samples in space and in time were classified into four clusters (Fig. 5). According to the distribution gradients of species on the SOM map, samples as well as species could be assessed effectively. The main property of the SOM is the dimension reduction achieved by the learning process. High-dimensional input data is mapped into low dimensions (commonly a 2-dimensional map), with information on the relationships between input signals preserved as much as possible. Through this process, neighbouring input values are mapped onto neighbouring (or the same) nodes according to some metric defined in the output space and neighbourhood topology is preserved. Additionally, the SOM averages the input dataset in weight vectors through the learning process and thus removes noise (Vesanto et al. 1998). The averaging effect was implemented in the first step of the combined model in this study. It is well known that classical clustering techniques are sensitive to the presence of outliers in the data. Therefore, outliers must be detected before analyzing clusters. However, the problem of outliers is minimized in the SOM. Each outlier takes its place in one unit of the map, and only the weights of that unit and its nearest neighbours are affected. There is no effect on the other units. Likewise, scattered nodes on the map suggest the presence of an outlier (Lek \& Guégan 2000).

The effects of drought were clearly reflected by monthly changes of communities. The species richness was very low around September (August and October, i.e. the dry season). These characteristics were also well implemented in the SOM map. Samples of drought periods were located in the upper left areas of the SOM map, showing low species richness. Meanwhile samples showing relatively high species richness were located in the lower areas of the SOM map. Clus- ters defined by the SOM showed different habitat conditions at the sampling sites. Cluster I (i.e., sites St4-7) and cluster II (site St1) were characterised by high proportion of silt, whereas cluster III (sites St2, 5, 7,8 ) was characterised by relatively high coverage of pebbles and gravels. According to these differences of substrate composition, habitat suitability for species can be suggested. According to the species distribution in the SOM map in this study, cluster I was characterised mainly by Limnodrilus hoffmeisteri, cluster II was dominated by Micronecta scholtzi and Panarais sp., cluster III by Baetis neglectus, Cloeon gr. dipterum, and Cricotopus bicinctus, and cluster IV was characterised by Baetis pavidus, Caenis luctuosa, Rheocricotopus chalybeatus, and Tubifex tubifex. However, the distributions of species are also governed by many different environmental parameters. In particular, intermittent streams are severely influenced by flooding and drought. To determine macroinvertebrate abundances in intermittent streams of Portugal, substrate was not important factor, but temperature, conductivity, and drought were the most important factors (Pires et al. 2000).

In summary, the benthic macroinvertebrate fauna collected in the study intermittent river was very poor. Chironomidae was the dominant taxa, and species richness was very low around September, during the dry season. Through an adaptive learning algorithm, benthic macroinvertebrates were patterned and sampling sites were classified into four clusters according to similarities in their community composition. The clusters were mainly related to the downstream location of the sampling sites, and to the presence of the above-mentioned dominant species. Finally, our results showed that the SOM approach provides an efficient characterization of the distribution patterns of aquatic organisms in the domains of space and time.

\footnotetext{
Acknowledgements

We are grateful to two anonymous reviewers for their insightful comments on an earlier draft of this manuscript.

\section{References}

Abell D.L. - 1984. Benthic invertebrates in some California intermittent streams. Pages 46-60 in Jain S. \& Moyle P. (eds.). Vernal pools and intermittent streams. Institute of Ecology Publication $\mathrm{n}^{\circ} 28$. UC Davis. Davis, CA.

Arab A. 1989. - Etude des peuplements d'invertébrés et de poissons appliquée à l'évaluation de la qualité des eaux et des ressources piscicoles des oueds Mouzaia et Chiffa. Thèse de magister I.S.N, U.S.T.H.B. Alger, 142 p.

Arscott D.B., Tockner K. \& Ward J. V. 2003. - Spatio-temporal patterns of benthic invertebrates along the continuum of a braided Alpine river. Arch. Hydrobiol., 158, 431-460.
} 
Belaidi N., Taleb J. \& Gagneur J. 2004. - Composition and dynamics of hyporheic and surface fauna in a semi-arid stream in relation to the management of a polluted reservoir. Ann. Limnol. - Int. J. Lim., 40, 237-248.

Benbow M.E., Burky A.J. \& Way C.M. 2003. - Life cycle of a torrenticolous Hawaiian chironomid (Telmatogeton torrenticola): stream flow and microhabitat effects. Ann. Limnol. - Int. J. Lim., 39, 103-114.

Bonada N. 2003. - Ecology of the macroinvertebrate communities in Mediterranean rivers at different scales and organization levels. Doctoral thesis. University of Barcelona, Barcelona, Spain. 355 p.

Boulton A.J. \& Suter P.J. - 1986. Ecology of temporary streams: an Australian perspective. Pages 313-327 in Limnology in Australia. de Decker P. \& Williams W.D. (eds). CSIRO/Dr. W. Junk. Melbourne / Dordrecht.

Boyero L. 2003. - The effect of substrate texture on colonization by stream macroinvertebrates. Ann. Limnol. - Int. J. Lim., 39, 211219.

Brown, J.H. 1984. - On the relationship between abundance and distribution of species. Am. Nat., 122, 295 - 299.

Brown J.H., Mehlman D.W. \& Stevens G.C. 1995. - Spatial variation in abundance. Ecology, 76, 2028 -2043.

Céréghino R., Park Y.S., Compin A. \& Lek S. 2003. - Predicting the species richness of aquatic insects in streams using a limited number of environmental variables. J. N. Am. Benthol. Soc., 22, 442456.

Chon T.S., Park Y.S., Moon K.H. \& Cha E.Y. 1996. - Patternizing communities by using an artificial neural network. Ecol. Model., 90, 69-78.

Comin F.A. \& Williams W.D. 1994. - Parched continents: our common future ? Pages 473-527 in Margalef R. (ed). Limnology now: a paradigm of planetary problems. Elsevier, Amsterdam.

Connell J. 1978. - Diversity in tropical rain forests and coral reefs. Science, 199, 1304-1310.

Curry R. 1972. - Rivers: a geomorphic and chemical overview. Pages 9-31 in Oglesby R.T., Carlson C.A., \& McCann J.A. (eds.) River Ecology \& Man. Academic Press, NY.

Daborn G.R. \& Clifford H.F. 1974. - Physical and chemical features of an aestival pond in western Canada. Hydrobiologia, 44, 43-59.

del Rosario R.B. \& Resh V.H. 2000. - Invertebrates in intermittent and perennial streams: is the hyporheic zone a refuge from drying? J. N. Am. Benthol. Soc., 19, 680-696.

Delucchi C.M. 1988. - Comparison of community structure among streams with different temporal flow regimes. Can. J. Zool., 66 , 579-586.

Dieterich M. \& Anderson N. H. 2000. - The invertebrate fauna of summer-dry streams in western Oregon. Arch. Hydrobiol., 147 273-295.

Gagneur J., Giani N. \& Martinez-Ansemil E. 1986. - Les oligochètes d'Algérie. Bull. Soc. Hist. Nat. Toulouse, 122, 119-124.

Gasith A. \& Resh V.H. 1999. - Streams in Mediterranean climate regions: abiotic influences and biotic responses to predictable seasonal events. Ann. Rev. Ecol. Syst., 30, 51-81.

Giraudel J.L. \& Lek S. 2001. - A comparison of self-organizing map algorithm and some conventional statistical methods for ecological community ordination. Ecol. Model., 146, 329-339.

Giudicelli J., Dakki M. \& Dia A. 1985. - Caractéristiques abiotiques et hydrobiologiques des eaux courantes méditerranéennes. Verh. Internat. Verein. Limnol., 22, 2094-2101.

González J.M., Basaguren A. \& Pozo J. 2003. - Macroinvertebrate communities along a third-order Iberian stream. Ann. Limnol. Int. J. Lim., 39, 287-296.

Grubaugh J.W., Wallace J.B. \& Houston E.S. 1996. - Longitudinal changes of macroinvertebrate communities along an Appalachian stream continuum. Can. J. Fish Aquat. Sci., 53, 896-909.
Harper P.P. \& Hynes H.B.N. 1970. - Diapause in the nymphs of Canadian winter stoneflies. Ecology, 51, 424-427.

Hellawell J.M. 1986. - Biological indicators of freshwater pollution and environmental eanagement. Elsevier, London, 546 p.

Hynes H.B.N. 1970. - The Ecology of Running Waters. Liverpool University Press, Liverpool.

Ives A.R. \& Kopfer E.D. 1997. - Spatial variation in abundance created by stochastic temporal variation. Ecology, 78, 1907-1913.

Jørgensen S.E. \& Padisak J. 1996. - Does the intermediate disturbance hypothesis comply with thermodynamics? Hydrobiologia, $323,9-21$.

Kohonen T. 2001. - Self-organizing maps. Springer, Berlin, 501 p.

Legendre P. \& Legendre L. 1998. - Numerical ecology. Elsevier, Amsterdam, $853 \mathrm{p}$.

Legier P. \& Talin J. 1973. - Comparaison de ruisseaux permanents et temporaires de la provence calcaire. Ann. Limnol., 9, 273- 292.

Lehmkhul D.M. 1973. - A new species of Baetis from ponds in the Canadian Arctic, with biological notes. Can. Entomol., 10, 343346.

Lek S. \& Guégan J.F. (eds). - Artificial neuronal networks: application to ecology and evolution. Springer, Berlin.

Lounaci A., Brosse S., Thomas A. \& Lek S. 2000. - Abundance, diversity and community structure of macroinvertebrates in an Algerian stream: the Sébaou wadi. Ann. Limnol. - Int. J. Lim., 36, 123-133.

Macan T.T. 1939. - Notes on the migration of some aquatic insects. J. Soc. British Entomol., 2, 1-6.

McIntosh M.D., Benbow M.E. \& Burky A.J. 2003. - Effect of water removal on introduced caddisflies from a tropical mountain stream. Ann. Limnol. - Int. J. Lim., 39, 297-306.

Margalef R. 1958. - Information theory in ecology. Gen Syst., 3, 3671.

Miller A.M. \& Golladay S.W. 1996. - Effects of spates and drying on macroinvertebrate assemblages of an intermittent and a perennial prairie stream. J. N. Am. Benthol. Soc., 15, 670-689.

Milne B.T. 1991. - Heterogeneity as a multiscale characteristic of landscapes. Pages 32-69 in Kolasa J. \& Pickett S.T.A. (eds). Ecological heterogeneity. Springer-Verlag. New York.

Navas L. 1929. - Insectes névroptères et voisins de Barbarie (septième série). Bull. Soc. Hist. Nat Afr. N., 20, 57-60.

Palmer M.A. \& Poff N.L. 1997. - The influence of environmental heterogeneity on patterns and processes in streams. J. N. Am. Benthol. Soc., 16, 169-173.

Palmer M.A., Arenburger P., Botts P.S., Hakenkamp C.C. \& Reid J.W. 1995. - Disturbance and the community structure of stream invertebrates: patch-specific effects and the role of refugia. Freshwat. Biol., 34, 343-356.

Park, Y.S., Chon T.S., Kwak I.S., Kim J.K. \& Jorgensen S.E. 2001. Implementation of artificial neural networks in patterning and prediction of exergy in response to temporal dynamics of benthic macroinvertebrate communities in streams. Ecol. Model., 146 143-157.

Park Y.S., Céréghino R., Compin A. \& Lek S. 2003a. - Applications of artificial neural networks for patterning and predicting aquatic insect species richness in running waters. Ecol. Model., 160, 265280

Park, Y.S., Verdonschot P.F.M., Chon T.S. \& Lek S. 2003b. - Patterning and predicting aquatic macroinvertebrate diversities using artificial neural network. Water Res., 37, 1749-1758.

Park Y.S., Chang J., Lek S., Cao W. \& Brosse S. 2003c. - Conservation strategies for endemic fish species threatened by the Three Gorges Dam. Conserv. Biol., 17, 1748-1758.

Park Y.S., Chon T.S., Kwak I.S. \& Lek S. 2004. - Hierarchical community classification and assessment of aquatic ecosystems using artificial neural networks. Sci.Total Environ., 327, 105-122. 
Pires A.M., Cowx I.G. \& Coelho M.M. 1999. - Seasonal changes in fish community structure of intermittent streams in the middle reaches of the Guadiana Basin (Portugal). J. Fish Biol., 54, 235249.

Pires A.M., Cowx I.G. \& Coelho M.M. 2000. - Benthic macroinvertebrate communities of intermittent streams in the middle reache of the Guadiana Basin (Portugal). Hydrobiologia, 435, 167-175.

Puckridge J.T., Sheldon, F., Walker, K.F. \& Boulton A.J. 1998. Flow variability and the ecology of large rivers. Mar. Freshwat. Res., 49, 55-72.

Reice S.R. 1985. - Experimental disturbance and the maintenance of species diversity in a stream community. Oecologia, 67, 90 -97.

Reiche M.L. 1869. - Catalogue des coléoptères d'Algérie et des contrées voisines avec description d'espèces nouvelles. Mém. Soc. Limnol. Normandie 15-44.

Richards C., Host G.E. \& Arthur J. W. 1993. - Identification of predominant environmental factors structuring stream macroinvertebrate communities within a large agricultural catchment. Freshwat. Biol., 29, 285-294

Schneider D.W. \& Frost T.M. 1996. - Habitat duration and community structure in temporary ponds. J. N. Am. Benthol. Soc., 15, 64 86.

Seurat L.G. 1922. - Faune des eaux continentales de la Berbérie. Bull. Soc. Hist. Nat. Afr. N., 13, 43-60, 77-92, 109-140.

StatSoft, Inc. 2002. - STATISTICA (data analysis software system), www.statsoft.com.

Statzner B. \& Higler B. 1986. - Stream hydraulics as a major determinant of benthic invertebrate zonation patterns. Freshwat. Biol. 16, 127-139.

Statzner B., Elouard J.M. \& Dejoux C. - 1987. Field experiments on the relationship between drift and benthic densities of aquatic insects in tropical streams (Ivory Coast). III. Trichoptera. Freshwat. Biol., 17, 391- 404.

Tate C.M. \& Heiny J.S. 1995. - The ordination of benthic invertebrate communities in the South Platte River Basin in relation to environmental factors. Freshwat. Biol., 33, 439-454.

Thienemann A. 1954. - Chironomus. Leben, Verbreitung und wirtschaftliche Bedeutung der Chironomiden. Binnengewässer, 20, 1 834.

Townsend C.R. \& Hildrew A.G. 1984. - Longitudinal pattern in detritivore communities of acid streams: a consideration of alternative hypotheses. Verh. Int. Ver. Theor. Angew. Limnol., 22, 19531958
Townsend C.R, Scarsbrook M.R. \& Dolédec S. 1997. - Quantifying disturbance in streams: alternative measures of disturbance in relation to macroinvertebrate species traits and species richness. $J$. N. Am. Benthol. Soc., 16, 531-544.

Vannote R.L. \& Sweeney B.W. 1980. - Geographic analysis of thermal equilibria: A conceptual model for evaluating the effect of natural and modified thermal regimes on aquatic insect communities. Am. Nat., 115, 667- 695.

Vesanto J., Himberg J., Siponen M. \& Simula O. 1998. - Enhancing SOM based visualization. Pages 64-67 in Proceedings of the 5th International Conference on Soft Computing and Information/Intelligent Systems (IIZUKA'98), Iizuka, Japan.

Ward J.V. 1985. - Thermal characteristics of running waters. Hydrobiologia, 125, 31- 46.

Ward J.V. 1989. - The four-dimensional nature of lotic ecosystems. J. N. Amer. Benthol. Soc., 8, 2-8.

Welcomme R.L. 1979. - Fisheries Ecology of Floodplain Rivers. Longman, London.

Wiggins G.B. 1973. - A contribution to the biology of caddisflies (Trichoptera) in temporary pools. Life Sci. Contr. Royal Ontario Museum, 88,1-28.

Wiggins G.B., Mackay R.J. \& Smith I.M. 1980. - Evolutionary and ecological strategies of animals in annual temporary pools. Arch. Hydrobiol. Supplement, 58, 97-206.

Williams D.D. \& Hynes H.B.N. 1976. - The ecology of temporary streams I. The faunas of two Canadian streams. Int. Rev. Gesamten Hydrobiol., 61, 761-787.

Williams D.D. \& Hynes H.B.N. 1977. - The ecology of temporary streams II. General remarks on temporary streams. Int. Rev. Ge samten Hydrobiol., 62, 53-61.

Williams D.D. 1987. - The ecology of temporary waters. Croom Helm Press, London.

Williams D.D. 1996. - Environmental constraints in temporary fresh waters and their consequences for the insect fauna. J. N. Am Benthol. Soc., 15, 634-650.

Wood D.M., Dang P.T. \& Ellis R.A. 1979. - The mosquitoes of Canada (Diptera: Culicidae). The insects and arachnids of Canada part 6. Agriculture Canada Publication 1686.

Wright J.F., Hiley P.D., Cooling D.A., Cameron A.C., Wigham M.E \& Berrie A.D. 1984. - The invertebrate fauna of a small chalk stream in Berkshire, England, and the effect of intermittent flow. Arch. Hydrobiol., 99, 176-199. 